\title{
Curcumin blocks migration and invasion of mouse-rat hybrid retina ganglion cells (N18) through the inhibition of MMP-2, -9, FAK, Rho A and Rock-1 gene expression
}

\author{
HUI-JU LIN ${ }^{1}$, CHIN-CHENG SU ${ }^{2}$, HSU-FENG LU ${ }^{3,4}$, JAI-SING YANG ${ }^{5}$, SHU-CHUN HSU ${ }^{6}$, SIU-WAN IP ${ }^{6}$, \\ JIA-JIUAN WU ${ }^{6}$, YU-CHING LI ${ }^{7}, \mathrm{CHIN}_{-\mathrm{CHIN} \mathrm{HO}}{ }^{8}, \mathrm{CHIH-CHUNG} \mathrm{WU}{ }^{9}$ and JING-GUNG $\mathrm{CHUNG}^{10}$ \\ ${ }^{1}$ Department of Ophthalmology, China Medical University Hospital, Taichung 404; ${ }^{2}$ Division of General Surgery, \\ Buddhist Tzu Chi General Hospital, Tzu Chi University, Hualien 970; ${ }^{3}$ Department of Clinical Pathology, \\ Cheng Hsin Rehabilitation Medical Center, Taipei 112; ${ }^{4}$ College of Human Ecology, Fu-Jen University, \\ Taipei 510; ${ }^{5}$ Department of Pharmacology, ${ }^{6}$ School of Nutrition, China Medical University, Taichung 404; \\ ${ }^{7}$ Department of Medical Laboratory Science and Biotechnology, Central Taiwan University of Science and \\ Technology; ${ }^{8}$ Department of Nursing, Central Taiwan University of Science and Technology, Pei-Tun \\ District, Taichung 406; ${ }^{9}$ Department of Health Sciences, Chang Jung Christian University, Tainan 711; \\ ${ }^{10}$ Department of Biological Science and Technology, China Medical University, Taichung 404, Taiwan
}

Received July 29, 2009; Accepted November 3, 2009

DOI: $10.3892 /$ or_00000682

\begin{abstract}
Cancer metastasis involves multiple processes which may complicate clinical management and even lead to death. Matrix metalloproteinases (MMPs) play an important role in cancer cell invasion, metastasis and angiogenesis, depending on whether agents can inhibit MMPs which could lead to inhibition of the migration and invasion of cancer cells. Curcumin, the active constituent of the dietary spice turmeric, has potential for the prevention and therapy of cancer. However, there is no study to address the effects of curcumin on migration and invasion of mouse-rat hybrid retina ganglion cells (N18). This is the first study to explore the anti-migration and -invasion of curcumin in mouse-rat hybrid retina ganglion cells (N18) in vitro. Curcumin exerted a dose- and time-dependent inhibitory effect on the invasion and migration of N18 cells in vitro. Results from Western blotting showed that curcumin inhibited the protein levels of PKC, FAK, NF-кB p65 and Rho A leading to the inhibition of ERK1/2, MKK7, COX-2 and ROCK1, respectively, finally causing the inhibition of MMP-2 and -9 for the inhibition of migration and invasion of N18 cells. Moreover, this action was involved in the inhibition of gene expression of MMP-2 and -7, FAK, ROCK1 and Rho A. Overall, the above data show that the anticancer effect of curcumin also exists for the
\end{abstract}

Correspondence to: Dr J.-G. Chung, Department of Biological Science and Technology, China Medical University, No 91, HsuehShih Road, Taichung City 404, Taiwan, R.O.C.

E-mail: jgchung@mail.cmu.edu.tw

Key words: curcumin, migration, invasion, matrix metalloproteinases, N18 mouse-rat hybrid ganglion cells inhibition of migration and invasion in N18 cells, and that curcumin may be a powerful candidate for developing preventive agents for cancer metastasis.

\section{Introduction}

Many types of neoplasms possess higher levels of activated matrix metalloproteinases (MMPs) that have been demonstrated in more invasive and/or metastatic tumors (1). The interactions between cells and the extracellular matrix (ECM) could enhance cell migration, invasion and ECM degradation. Metastasis of cancer is involved in the degradation of ECM and the overexpression of MMPs and u-PA $(2,3)$. Many epidemiological and laboratory studies have shown that dietary agents play an important role in reducing cancer risk (4-6). Moreover, substantial research suggests that numerous naturally occurring compounds can act as antioxidants, cancer preventative and therapeutic agents (7-9). Many prescription drugs in clinical used for cancer patients are derived from natural plant species $(10,11)$.

Curcumin (diferuloylmethane) is an active component from the spice turmeric (Curcuma longa). Curcumin has been reported to have chemopreventive and therapeutic properties against many tumors in vitro and in vivo models $(12,13)$. Curcumin inhibited cell proliferation and inflammation and caused cell cycle arrest and apoptosis in many types of cancer cells (14-16). In particular it can suppress invasion, angiogenesis, and metastasis of cancer cells (14). It is well known that the biological activities of curcumin involve Akt, activator protein-1, cyclooxygenase-2 lipoxygenase, nuclear factor- $\kappa \mathrm{B}, \mathrm{I} \kappa \mathrm{B} \alpha$ kinase, mitogen-activated protein kinases (MAPK) tumor necrosis factor, chemokines, and cell cycle machinery and Akt/mTOR signaling (15,17-24). Our previous studies have shown that curcumin induced cell cycle arrest and apoptosis (25) and DNA damage and 
inhibited DNA repair associated gene expression (26) in mouse-rat hybrid retina ganglion cells (N18). However, the effects of curcumin on migration and invasion of mouse-rat hybrid retina ganglion cells (N18) and the mechanisms underlying these effects have not been studied.

In the present study, we examined whether curcumin inhibits migration and invasion of N18 cells. We demonstrated that curcumin potently inhibits the migration and invasion of mouse-rat hybrid retina ganglion cells (N18), an effect which may be mediated through inhibition of MMP-2 and MMP-7 signaling.

\section{Materials and methods}

Materials and chemicals. Curcumin, dimethyl sulfoxide (DMSO), pyruvate, penicillin G, trypan blue, triton X-100 and streptomycin were purchased from Sigma Chemical (St. Louis, MO, USA). Anti-MMP-2, anti-MMP-9, anti-ERK, anti-c-jun-p, anti-FAK, anti-GRB2, anti-JNK, anti-MEKK3, anti-MKK7, anti-PI3K, anti-PKC, anti-Ras, anti-VEGF and anti-Rho A were purchased from Santa Cruz Biotechnology. Materials and chemicals for electrophoresis were obtained from Bio-Rad.

Cell culture. Mouse-Rat Hybrid retina ganglion cell line (N18: derived from retina ganglion cells hybrid with lymphoma cells) was purchased from the Japanese Collection of Research Bioresources Bank. N18 cells are placed onto the $75 \mathrm{~cm}^{2}$ flasks with DMEM medium supplemented with $10 \%$ FBS, $1 \%$ penicillin-streptomycin $(100 \mathrm{U} / \mathrm{ml}$ penicillin and $100 \mu \mathrm{g} /$ $\mathrm{ml}$ streptomycin) and $2 \mathrm{mM}$ L-glutamine and were cultured in a humidified atmosphere of $5 \% \mathrm{CO}_{2}$ and $95 \%$ air at $37^{\circ} \mathrm{C}$ as described previously $(10,26)$.

Transwell migration assay. N18 cells were serum deprived in DMEM medium supplemented with $1 \%$ charcoal-stripped FBS and maintained for $24 \mathrm{~h}$. The lower side of the Transwell filter was pre-coated with $10 \mu \mathrm{g}$ Type IV collagen. Then from each well, DMEM containing 1\% charcoal-stripped FBS was added. The filter in 6.5-mm Transwell was inserted in 24-well plates. Then $\sim 2.5 \times 10^{4}$ cells/filter of N18 cells were placed on the filter and cells were treated with $0,7.5$ and $15 \mu \mathrm{M}$ curcumin for 24 and $48 \mathrm{~h}$. Migrated cells were stained with hematoxylin and eosin (H\&E) and then were examined and photographed under a microscope $(11,26)$.

Transwell invasion assay. The same protocols were performed as described in the migration assay except that cells were placed on a matrigel-coated Transwell filter (Matrigel invasion chamber, BD Biosciences) and then examined and photographed under a microscope $(11,26)$.

Western blot analysis. N18 cells (1x10\%/well) in DMEM medium were plated onto 6-well plates and then were treated with $15 \mu \mathrm{M}$ curcumin for $0,6,12,24$ and $48 \mathrm{~h}$. After treatment in each time point, cells from each well were harvested and isolated by centrifugation in 1,500 rpm for $5 \mathrm{~min}$. The isolated cells from each treatment were lysed individually and the total protein levels were quantified. To determine the proteins levels associated with invasion and
Table I. The DNA sequence was evaluated using the Primer Express software.

Primer name Primer sequence

Rat MMP2-F CTTGCTGGTGGCCACATTC

Rat MMP2-R CTCATTCCCTGCGAAGAACAC

Rat MMP7-F GATGGGCCAGGAAACACTCTAG

Rat MMP7-R CCTCACCATCCGTCCAGTACTC

Rat MMP9-F-2 CGCTCATGTACCCCATGTATCA

Rat MMP9-R-2 TCAGGTTTAGAGCCACGACCAT

Rat FAK-F AGGGAGGACGGGAGTTTTCA

Rat FAK-R GGCGAGGTGGTTTCTTTGG

Rat Rho-F

Rat Rho-R TCATGGTCTTCGGAGGATTCA

Rat ROCK1-F GTGGCAAAGAAGCCCTCAAG

Rat ROCK1-R ATTCATTCCTACССТCTACCACTTTC

Rat GAPDH-F GGTGGACCTCATGGCCTACA

Rat GAPDH-R CAGCAACTGAGGGCCTCTCT

Each assay was conducted at least twice to ensure reproducibility.

migration (Ras, GRB2, MEKK3, FAK, MKK7, JNK, ERK, MMP-9, MMP-2, Rho A, PI3K, PKC, VEGF and c-jun-p) in N18 cells, all samples were separated by sodium dodecyl sulfate polyacrylamide gel electrophoresis (SDS-PAGE) as described previously $(11,26,27)$.

Real-time PCR of MMP-2, MMP-7, FAK, Rho A and ROCK1 in N18 mouse-rat hybrid retina ganglion cells. N18 cells (1x106/wells) in DMEM medium were plated onto 6-well plates and then were treated with $15 \mu \mathrm{M}$ curcumin for 24 and $48 \mathrm{~h}$. Cells were isolated from each treatment and the total RNA was extracted using the Qiagen RNeasy mini kit as described previously (27-29). All RNA samples were reversetranscribed individually for $30 \mathrm{~min}$ at $42^{\circ} \mathrm{C}$ with high capacity cDNA Reverse transcription kit according to the standard protocol of the supplier (Applied Biosystems). The quantitative PCR from each sample was performed by the condition: $2 \mathrm{~min}$ at $50^{\circ} \mathrm{C}, 10 \mathrm{~min}$ at $95^{\circ} \mathrm{C}$, and 40 cycles of $15 \mathrm{sec}$ at $95^{\circ} \mathrm{C}, 1 \mathrm{~min}$ at $60^{\circ} \mathrm{C}$ using $1 \mu \mathrm{l}$ of the cDNA reverse-transcribed as described above, 2X SYBR Green PCR master mix (Applied Biosystems) and $200 \mathrm{nM}$ of forward and reverse primers as shown in Table I. Each assay was run on an Applied Biosystems 7300 Real-Time PCR system in triplicates and expression fold-changes were derived using the comparative $\mathrm{C}_{\mathrm{T}}$ method $(27,29,30)$.

Statistical analysis. The differences between the curcumintreated and control group were analyzed by Student's t-test.

\section{Results}

Curcumin inhibits the migration of N18 cells in vitro. Representative pictures are shown in Fig. 1A and the percentage of inhibition is shown in Fig. 1B, and both results 
A

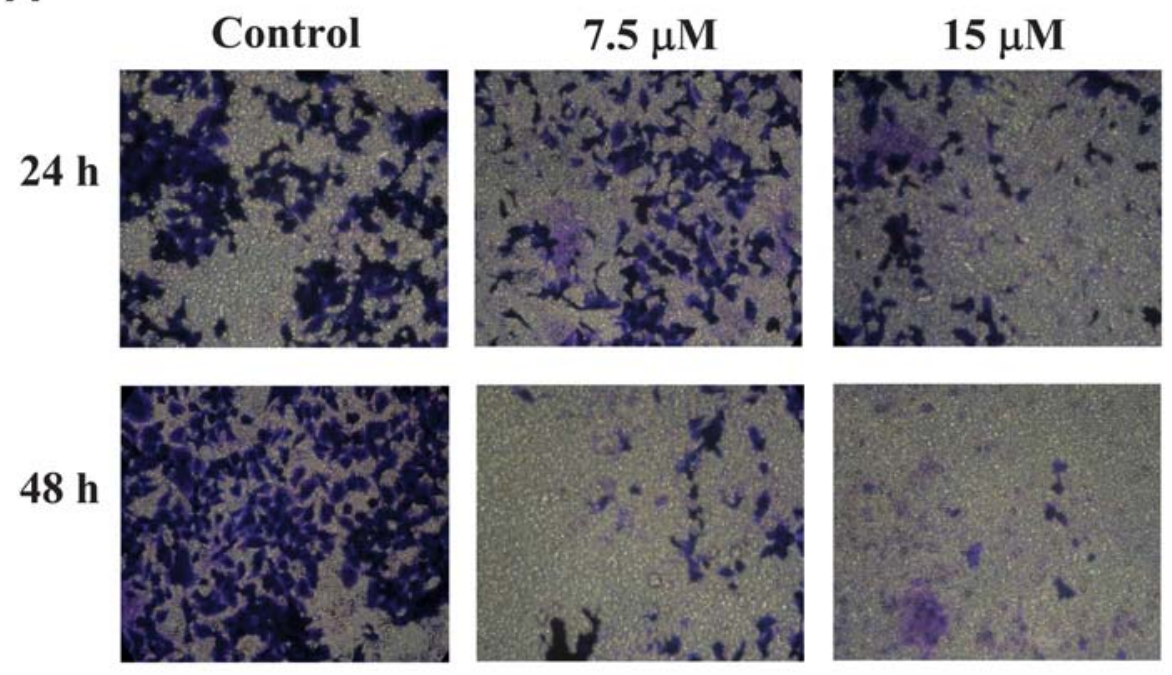

B

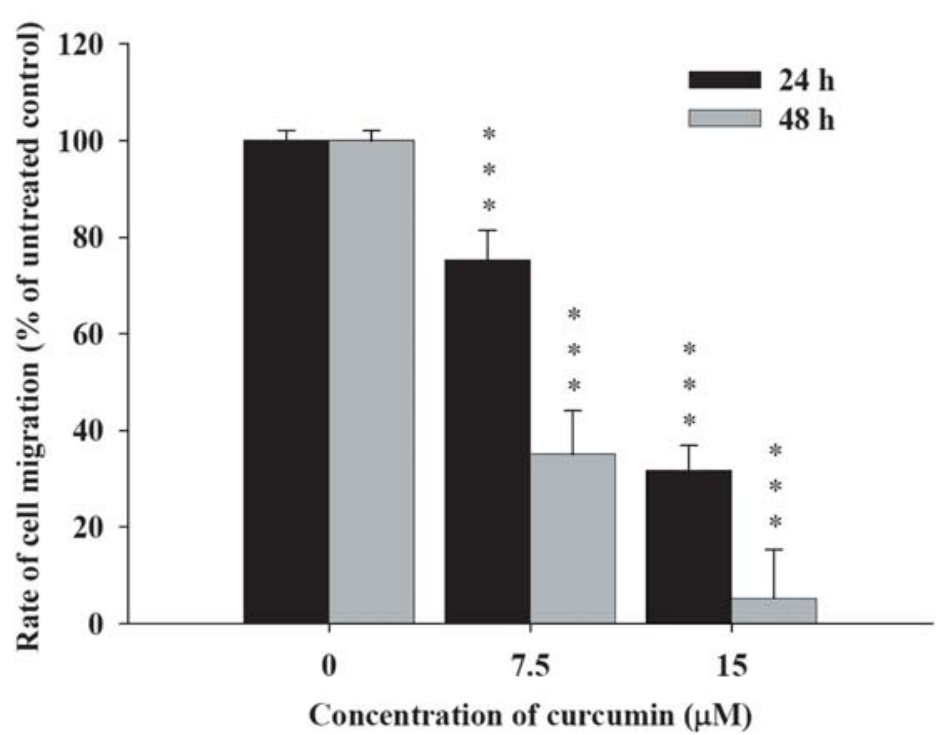

Figure 1. Curcumin inhibited the migration of N18 cells in vitro. The filter in 6.5 -mm Transwell was inserted in 24 -well plates. Then $2.5 \times 10^{4}$ cells/filter of N18 cells were placed on the filter and cells were treated with $0,7.5$ and $15 \mu \mathrm{M}$ curcumin for 24 and $48 \mathrm{~h}$. Migrated cells were stained with hematoxylin and eosin (H\&E) and then were examined and photographed under microscope (x200). Quantification of cells in the lower chamber was performed by counting cells at $\mathrm{x} 200(\mathrm{~B}) .{ }^{* * *} \mathrm{P}<0.001$, significant difference between curcumin-treated groups and the control.

indicated that curcumin inhibited N18 cell migration. The higher dose of curcumin and the longer $(48 \mathrm{~h})$ incubation time period of N18 cells lead to greater inhibition of cell migration, and the percentage of inhibition ratio is $62-94 \%$. These effects were dose- and time-dependent.

Curcumin inhibits the invasion of N18 cells in vitro. The inhibition of curcumin on the N18 cells invasion was examined and results are shown in Fig. 2A and B. Fig. 2A shows that N18 cells invaded from the upper to the lower chamber in majority of cells when compared to the control group, but the penetration of the matrigel-coated filter by N18 cells was inhibited in the presence of curcumin. This inhibitory effect was higher at a curcumin concentration of $15 \mu \mathrm{M}$ than $7.5 \mu \mathrm{M}$. The quantification of cells in the lower chamber when compared to the upper chamber chamber group from Fig. 2B indicated that curcumin significantly inhibited N18 cell invasion, the inhibition range was $80-84 \%$ at $24 \mathrm{~h}$ and these effects were dose- and time-dependent.

Curcumin inhibits the levels of mRNA expression in N18 cells. To confirm that curcumin inhibited the migration and invasion of N18 cells, and ultimately resulted in the alterations of the expression of these genes at the mRNA level, which are associated with protein levels, we conducted a series of real-time PCR analyses for examining the levels of MMP-2, MMP-7, FAK, Rho A and ROCK1 and the results are shown in Fig. 3 which indicated that expression levels of MMP-2, MMP-7, FAK, Rho A and ROCK1 mRNA were decreased. These effects were time-dependent.

Curcumin inhibits levels of GRB2, Ras, PKC, MKK7, FAK, Rho A, ROCK1, MMP-2, MMP-9, iNOS, NF-кB p65, COX-2, $J N K 1 / 2$ and ERK1/2 in N18 cells. Levels of invasion- and 
A
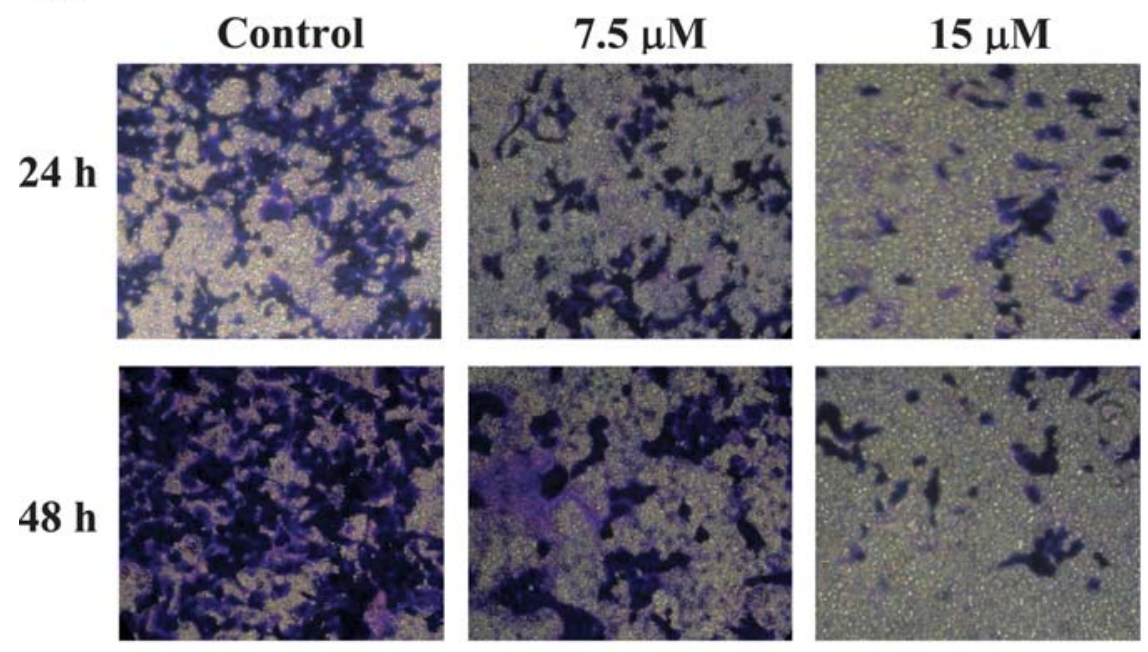

B

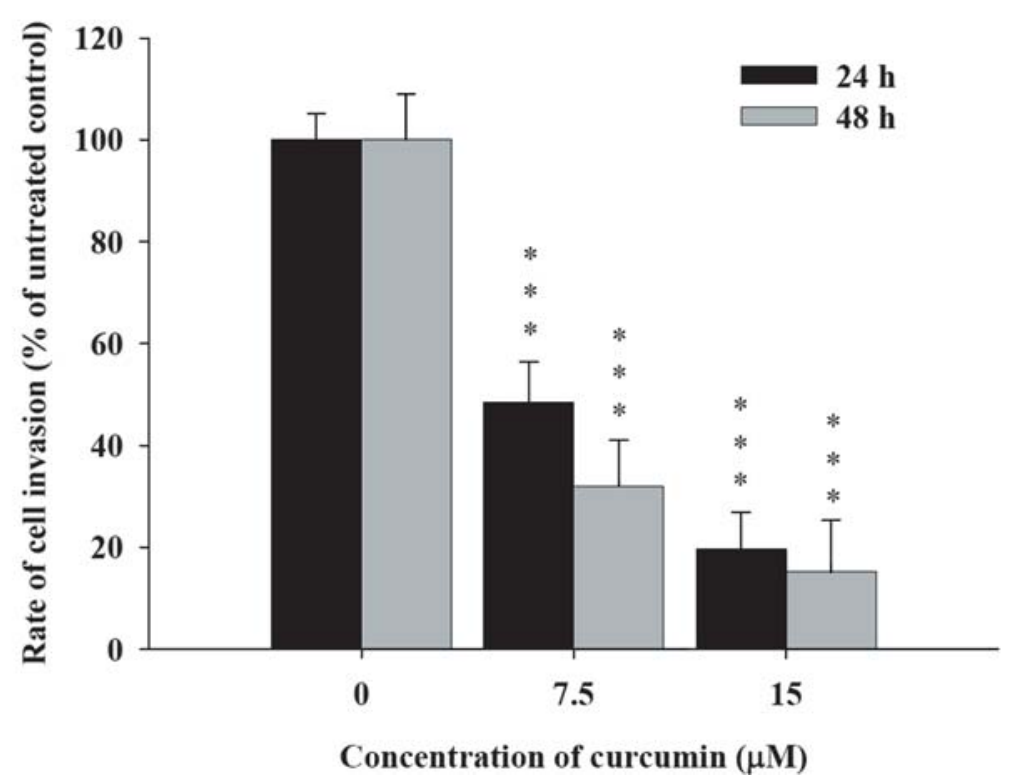

Figure 2. Curcumin inhibited the invasion of $\mathrm{N} 18$ cells in vitro. $\mathrm{N} 18$ cells $\left(10^{4}\right.$ cells/ $0.4 \mathrm{ml}$ DMEM medium $)$ were placed and cells that penetrated through the matrigel to the lower surface of the filter were stained with crystal violet and were photographed under a light microscope at x200 (A). Quantification of cells in the lower chamber was performed by counting cells at x200 (B) ${ }^{* * *} \mathrm{P}<0.001$, significant difference between curcumin-treated groups and the control.

migration-associated proteins in N18 cells after treatment with 7.5 and $15 \mu \mathrm{M}$ of curcumin were determined and quantitated by Western blotting. Results presented in Fig. 4 indicate that the levels of GRB2, Ras, PKC, MKK7, FAK, Rho A, ROCK1, MMP-2, MMP-9, iNOS, NF-кB p65, COX-2, JNK1/2 and ERK1/2 were lower than the corresponding control group. MMP-2 and -9 play an important role in cell invasion and migration and these effects may lead to the inhibition of invasion and migration of N18 cells.

\section{Discussion}

Many studies have shown that curcumin exhibits anticancer activity and is associated with the molecular mechanism. It is also being observed for cell cycle arrest and induction of apoptosis. Our previous studies also showed that curcumin decreased the percentage of viable N18 cells through G2/M phase arrest and apoptosis and those effects were dose- and time-dependent. We also found that curcumin induced DNA damage and inhibited DNA repair gene expression in N18 cells. However, actions of curcumin on migration and invasion of N18 cells and the possible signaling pathways have not been addressed. Herein, we found that curcumin suppressed the migration and invasion of N18 cells through the EEK3, FAK, Rho A and MKK7 pathway before leading to the inhibitions of MMP-2 and MMP-9. Other studies demonstrated that curcumin inhibited the invasion and metastasis in human lung adenocarcinoma (CL1-5) cells through activation of the tumor suppressor DnaJ-like heat shock protein 40 (HLJ1) through activation of the JNK/JunD pathway (23). It was reported that cell migration involves several growth factors for stimulating downstream signaling pathways to form cytoskeletal reorganization and stimulation of motility machinery of the cell (31), and they also provide multiple 


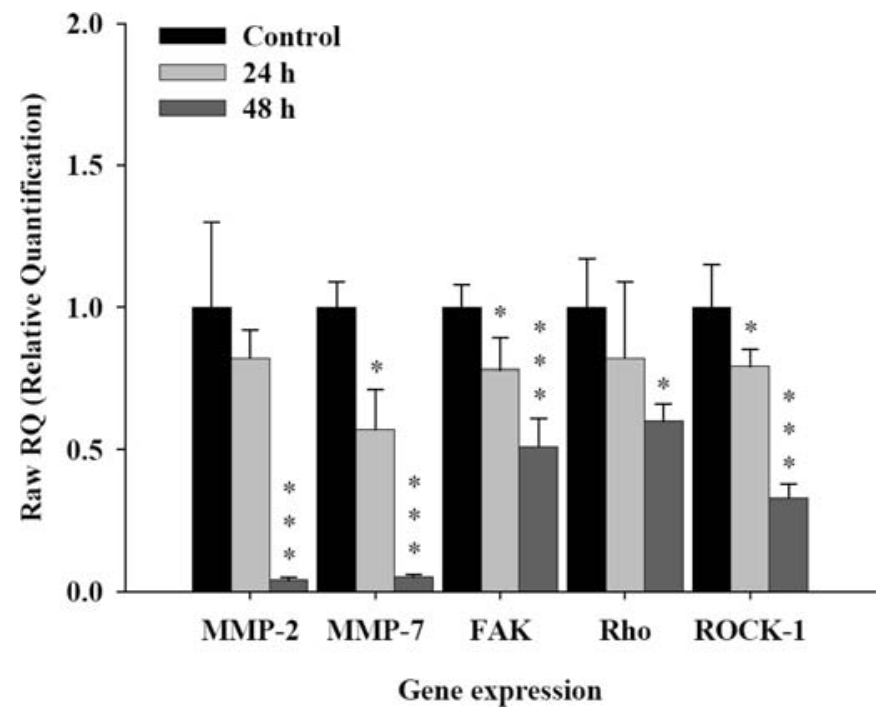

Figure 3. Curcumin inhibited the mRNA expression of migration and invasion in $\mathrm{N} 18$ cells. Cells were treated with $15 \mu \mathrm{M}$ curcumin for 0,24 and $48 \mathrm{~h}$ and then the total RNA was prepared. The evaluation of the gene expression was carried out by real-time PCR for examining the mRNA expression levels of MM-2, MMP-7, FAK, Rho A and ROCK1. Significantly different between curcumin and control treated groups $\left({ }^{*} \mathrm{P}<0.05\right.$; $\left.{ }^{* *} \mathrm{P}<0.01 ;{ }^{* * *} \mathrm{P}<0.001\right)$.
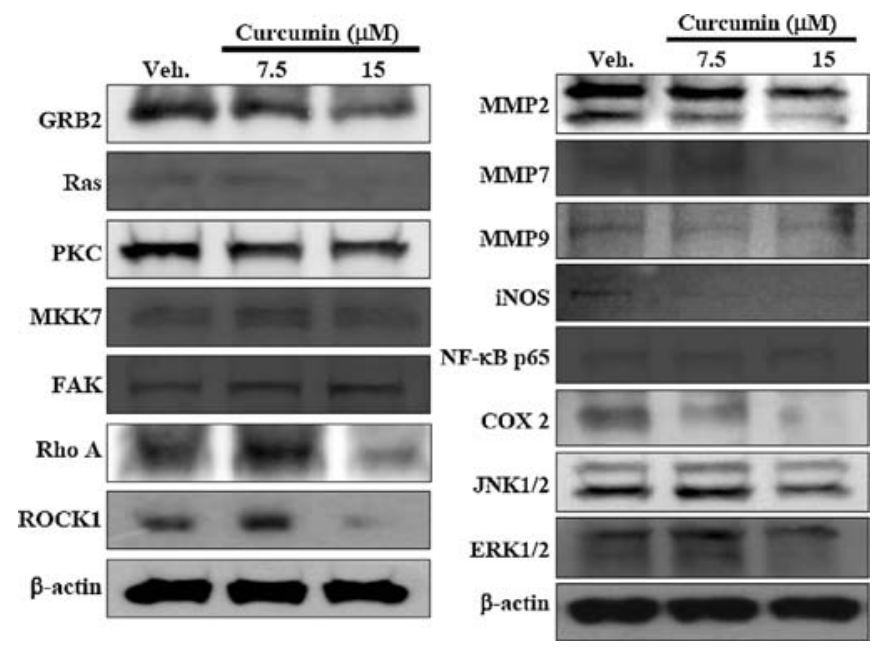

Figure 4. Curcumin inhibited the levels of associated proteins in migration and invasion of N18 cells. The N18 cells $\left(1 \times 10^{6}\right.$ cells/well) were treated with curcumin at 7.5 and $15 \mu \mathrm{M}$ for $48 \mathrm{~h}$ before total protein was prepared and determined from each sample, as described in Materials and methods. The levels of GRB2, Ras, PKC, MKK7, FAK, Rho A, ROCK1, MMP-2, MMP-7, MMP-9, iNOS, NF-кB p65, COX-2, JNK1/2 and ERK1/2 expressions were estimated by Western blotting, as described in Materials and methods.

targets for the development of therapeutic agents to inhibit cancer invasion and metastasis $(32,33)$.

It is well known that cancer invasion is due to the cancer cells responding and migrating towards gradients of stimuli and that it requires proteolysis of basement membrane (BM) and extracellular matrix (ECM) proteins to create a path for migration. Matrix metalloproteinases (MMPs) are a multigene family of zinc-dependent endopeptidases responsible for the proteolysis of BM and ECM proteins (34), and the expression

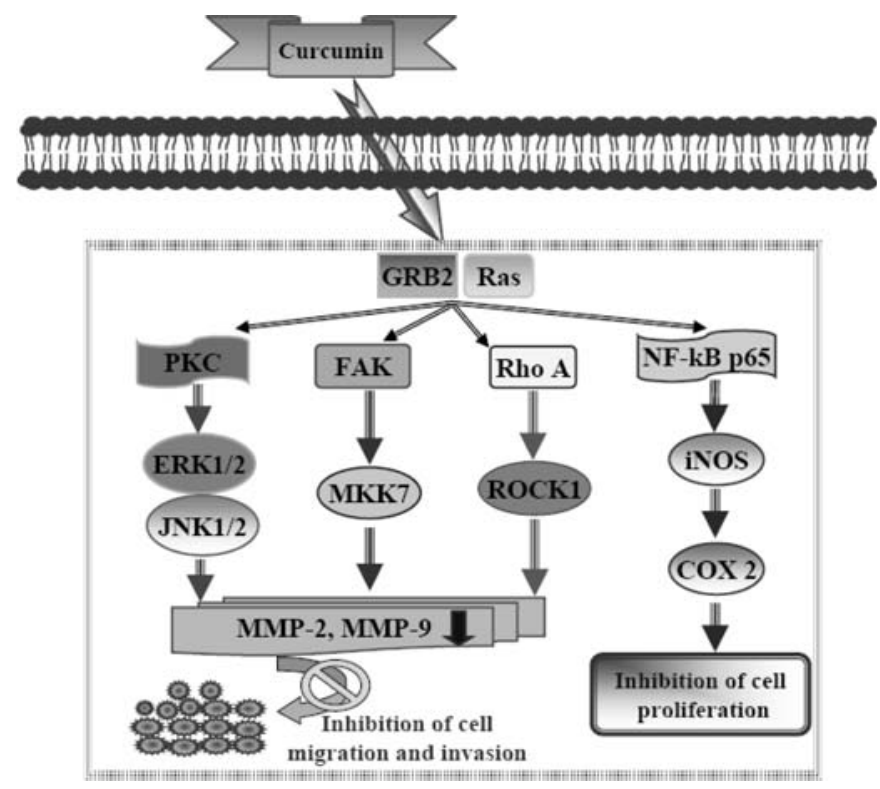

Figure 5. Molecular signaling pathways for curcumin-inhibited invasion and migration in mouse-rat hybrid ganglion cells.

level of MMPs appears to correlate with the invasiveness of cancer cells (35). Among MMPs, MMP-2 and MMP-9 play the most important role for basement membrane type IV collagen degradation $(23,31,32)$. The MMP-2 expression had been shown to be associated with tumor invasion, angiogenesis, metastasis and recurrence (36). In the present study, we found that curcumin inhibited the gene expression of MMP-2 and MMP-7 in N18 cells. It was reported that agents affecting MMPs may go through different mechanisms including direct inhibition of the enzymatic activity of MMPs, interference in the activation of pro-MMPs and reduced expression of MMP genes and protein levels (36). Thus, it seems quite likely that curcumin could inhibit or delay cancer invasion and migration in N18 cells via modulation of MMP-2 and -9.

Herein, our results already showed that curcumin inhibited the migration (Fig. 1A and B) and invasion (Fig. 2A and B) in N18 cells and those effects are dose-and time-dependent. We also showed that curcumin inhibited the expression of mRNA of MMP-2 and -7, Rho A, Rho kinases- ROCK-1 (ROCK-1) and focal adhesion kinase (FAK) in N18 cells (Fig. 4). ROCK-1 mediates some of the downstream signaling of Rho A (37) and is involved in regulation of cell adhesion and migration and therefore ROCK-1 could have potential therapeutic value in lung cancer (38).

Cell migration involves assembly and disassembly of focal adhesions. Furthermore, FAK is activated mainly in focal adhesions and it was reported that FAK plays an important in cell-ECM interactions that affect cell migration, proliferation and survival $(39,40)$. It is not known what concentrations of curcumin are reached in vivo under the conditions used in the present experiments. This will require further study. Therefore, the exact molecular signaling pathway for curcumin inhibiting the migration and invasion in N18 cells still needs further investigation.

Collectively, our data is the first finding to show that curcumin inhibited migration and invasion of human N18 
cells through MEKK, ERK and NF-кB signaling pathways resulting in the inhibition of MMP-2 and -9 as summarized in Fig. 5. Curcumin was recognized to be a therapeutic agent for inhibiting metastasis and invasion.

\section{Acknowledgements}

This work was supported by Grant NSC95-2745-B-039-002URD from National Science Council, Taiwan, R.O.C.

\section{References}

1. Muller D, Breathnach R, Engelmann A, et al: Expression of collagenase-related metalloproteinase genes in human lung or head and neck tumours. Int J Cancer 48: 550-556, 1991.

2. Gontero P, Banisadr S, Frea B, et al: Metastasis markers in bladder cancer: A review of the literature and clinical considerations. Eur Urol 46: 296-311, 2004.

3. Parks WC and Shapiro SD: Matrix metalloproteinases in lung biology. Respir Res 2: 10-19, 2001.

4. Sporn MB and Suh N: Chemoprevention of cancer. Carcinogenesis 21: 525-530, 2000.

5. Lippman SM and Hong WK: Cancer prevention science and practice. Cancer Res 62: 5119-5125, 2002.

6. Clinton SK and Giovannucci E: Diet, nutrition, and prostate cancer. Annu Rev Nutr 18: 413-440, 1998.

7. Parkin DM, Pisani P and Ferlay J: Estimates of the worldwide incidence of 25 major cancers in 1990. Int J Cancer 80: 827-841, 1999.

8. Hashibe M, Brennan P, Benhamou S, et al: Alcohol drinking in never users of tobacco, cigarette smoking in never drinkers, and the risk of head and neck cancer: Pooled analysis in the international head and neck cancer epidemiology consortium. J Natl Cancer Inst 99: 777-789, 2007.

9. Rahman M, Sakamoto J and Fukui T: Calculation of population attributable risk for bidi smoking and oral cancer in south Asia. Prev Med 40: 510-514, 2005.

10. Room R, Babor T and Rehm J: Alcohol and public health. Lancet 365: 519-530, 2005.

11. Balaram P, Sridhar H, Rajkumar T, et al: Oral cancer in southern India: The influence of smoking, drinking, paan-chewing and oral hygiene. Int J Cancer 98: 440-445, 2002.

12. Khor TO, Keum YS, Lin W, et al: Combined inhibitory effects of curcumin and phenethyl isothiocyanate on the growth of human PC-3 prostate xenografts in immunodeficient mice. Cancer Res 66: 613-621, 2006.

13. Sharma RA, Gescher AJ and Steward WP: Curcumin: The story so far. Eur J Cancer 41: 1955-1968, 2005.

14. Karunagaran D, Rashmi R and Kumar TR: Induction of apoptosis by curcumin and its implications for cancer therapy. Curr Cancer Drug Targets 5: 117-129, 2005.

15. Thangapazham RL, Sharma A and Maheshwari RK: Multiple molecular targets in cancer chemoprevention by curcumin. AAPS J 8: E443-E449, 2006.

16. Srivastava RK, Chen Q, Siddiqui I, et al: Linkage of curcumininduced cell cycle arrest and apoptosis by cyclin-dependent kinase inhibitor p21(/waf1/cip1). Cell Cycle 6: 2953-2961, 2007.

17. Chen HW and Huang HC: Effect of curcumin on cell cycle progression and apoptosis in vascular smooth muscle cells. Br J Pharmacol 124: 1029-1040, 1998.

18. Aggarwal S, Ichikawa H, Takada Y, et al: Curcumin (diferuloylmethane) down-regulates expression of cell proliferation and antiapoptotic and metastatic gene products through suppression of IKappabAlpha kinase and akt activation. Mol Pharmacol 69: 195-206, 2006.

19. Kim SY, Jung SH and Kim HS: Curcumin is a potent broad spectrum inhibitor of matrix metalloproteinase gene expression in human astroglioma cells. Biochem Biophys Res Commun 337: 510-516, 2005.
20. Aggarwal BB, Kumar A and Bharti AC: Anticancer potential of curcumin: Preclinical and clinical studies. Anticancer Res 23: 363-398, 2003

21. Beevers CS, Li F, Liu L, et al: Curcumin inhibits the mammalian target of rapamycin-mediated signaling pathways in cancer cells. Int J Cancer 119: 757-764, 2006.

22. Aoki H, Takada Y, Kondo S, et al: Evidence that curcumin suppresses the growth of malignant gliomas in vitro and in vivo through induction of autophagy: Role of Akt and extracellular signal-regulated kinase signaling pathways. Mol Pharmacol 72: 29-39, 2007.

23. Chen HW, Lee JY, Huang JY, et al: Curcumin inhibits lung cancer cell invasion and metastasis through the tumor suppressor HLJ1. Cancer Res 68: 7428-7438, 2008.

24. Kim JH, Xu C, Keum YS, et al: Inhibition of EGFR signaling in human prostate cancer PC-3 cells by combination treatment with beta-phenylethyl isothiocyanate and curcumin. Carcinogenesis 27: 475-482, 2006.

25. Lu HF, Lai KC, Hsu SC, et al: Curcumin induces apoptosis through fas and fadd, in caspase-3-dependent and -independent pathways in the N18 mouse-rat hybrid retina ganglion cells. Oncol Rep 22: 97-104, 2009.

26. Lin SS, Lai KC, Hsu SC, et al: Curcumin inhibits the migration and invasion of human a549 lung cancer cells through the inhibition of matrix metalloproteinase-2 and -9 and vascular endothelial growth factor (VEGF). Cancer Lett (In press).

27. Lin JG, Chen GW, Li TM, et al: Aloe-emodin induces apoptosis in $\mathrm{t} 24$ human bladder cancer cells through the p53 dependent apoptotic pathway. J Urol 175: 343-347, 2006.

28. Hsu SC, Kuo CL, Lin JP, et al: Crude extracts of euchresta formosana radix induce cytotoxicity and apoptosis in human hepatocellular carcinoma cell line (hep3b). Anticancer Res 27: 2415-2425, 2007.

29. Lu KH, Lue KH, Chou MC, et al: Paclitaxel induces apoptosis via caspase-3 activation in human osteogenic sarcoma cells (u2os). J Orthop Res 23: 988-994, 2005.

30. Hsu MH, Chen CJ, Kuo SC, et al: 2-(3-fluorophenyl)-6-methoxyl4-oxo-1,4-dihydroquinoline-3-carboxylic acid (YJC-1) induces mitotic phase arrest in A549 cells. Eur J Pharmacol 559: 14-20, 2007.

31. Anand-Apte B and Zetter B: Signaling mechanisms in growth factor-stimulated cell motility. Stem Cells 15: 259-267, 1997.

32. Price JT and Thompson EW: Mechanisms of tumour invasion and metastasis: Emerging targets for therapy. Expert Opin Ther Targets 6: 217-233, 2002.

33. Fenteany $G$ and Zhu S: Small-molecule inhibitors of actin dynamics and cell motility. Curr Top Med Chem 3: 593-616, 2003.

34. Liotta LA, Steeg PS and Stetler-Stevenson WG: Cancer metastasis and angiogenesis: An imbalance of positive and negative regulation. Cell 64: 327-336, 1991.

35. Woodhouse EC, Chuaqui RF and Liotta LA: General mechanisms of metastasis. Cancer 80: 1529-1537, 1997

36. Hidalgo $\mathrm{M}$ and Eckhardt SG: Development of matrix metalloproteinase inhibitors in cancer therapy. J Natl Cancer Inst 93: 178-193, 2001.

37. Riento K and Ridley AJ: Rocks: Multifunctional kinases in cell behaviour. Nature Rev 4: 446-456, 2003.

38. Chen J, Ye L, Zhang L, et al: Placenta growth factor, PLGF, influences the motility of lung cancer cells, the role of rho associated kinase, ROCK1. J Cell Biochem 105: 313-320, 2008.

39. McLean GW, Carragher NO, Avizienyte E, et al: The role of focal-adhesion kinase in cancer - a new therapeutic opportunity. Nat Rev Cancer 5: 505-515, 2005.

40. Schlaepfer DD, Mitra SK and Ilic D: Control of motile and invasive cell phenotypes by focal adhesion kinase. Biochim Biophys Acta 1692: 77-102, 2004. 